\title{
The Mathematical Model of Spiral Bevel Gears - A Review
}

\author{
Jixin Wang 1 - Long Kong1, ${ }^{1}$ - Bangcai Liu ${ }^{2}$ - Xinpeng $\mathrm{Hu}^{1}$ - Xiangjun $\mathrm{Yu}^{3}$ - Weikang Kong1 \\ 1 Jilin University, School of Mechanical Science and Engineering, China \\ 2 XCMGH Hydraulic Component Co., Ltd, China \\ ${ }^{3}$ Kunming University, College of Automatic Control and Mechanical Engineering, China
}

The spiral bevel gear (SBG) is a key component of the power transmission of intersection axes. Since the mathematical model of the SBG is a basis for stress and thermal analysis, the optimization of machine-tool settings, frictional contact analysis in lubricated condition, and advanced manufacturing technology, research on designing and manufacturing of SBGs based on mathematical models of SBG has long been a topic of considerable interest in the field of mechanical transmission. The significance of research on the mathematical model lies not only in analysing and building the tooth surface model, but also in investigating the design principles and manufacturing processes. This paper conducts a comprehensive literature review regarding the mathematical modelling of SBGs. The methods of building mathematical models, such as the matrix method, the vector method and the geometry method, are illustrated, compared and summarized in detail. Furthermore, the research history and applications of each method of building a mathematical model of SBGs are presented for better understanding. Based on applications of the mathematical model of SBGs, it is also indicated that more manufacturing methods could be updated or explored with the future development of universal milling machine technologies and computer aided manufacturing methods.

Keywords: spiral bevel gear, mathematical model, matrix method, vector method, geometry method

\section{INTRODUCTION}

The spiral bevel gear (SBG), with its high contact ratio, high strength and smooth driving, is widely used to transmit dynamic power in various mechanical products, including vehicles, mining machinery, aerospace engineering, and helicopters [1] to [4]. Typical SBGs are shown in Figs. 1a and b. The SBG has been a subject of research for almost a century, and there is a significant amount of literature on the mathematical model of SBGs. The tooth surface of an SBG is a complicated curved surface with a kinematic performance directly bonded to the special cutting process [5]. The mathematical model has significantly contributed to the Computer-Aided Design and Manufacturing (CAD/CAM) of SBGs, because the mathematical model of SBG can be constructed to determine the processing method [6] and [7], to calculate machine-tool settings [8] to [11], to optimize tooth surface topography [12] to [15], to build models of Finite Element Analysis (FEA) [16] to [18], Tooth Contact Analysis (TCA) and Loaded Tooth Contact Analysis (LTCA) [19] to [21], and to develop new SBG types, as shown in Fig. 2. Therefore, the study of the mathematical model construction significantly influences the technological development of the SBG.

The most popular method of manufacturing SBGs is that used by Gleason, Oerlikon, and Klingeinberg. The basic structural forms of special machines include the traditional cradle-type hypoid and computer numerical control (CNC) hypoid generators. The typical feature and manufacturing principle of these special machines are to cut the workpiece using a rotating cutter head. To analyse the process of manufacturing SBGs, the mathematical model of the tooth surface can be considered to be a spatial trajectory of the cutter blade [22].

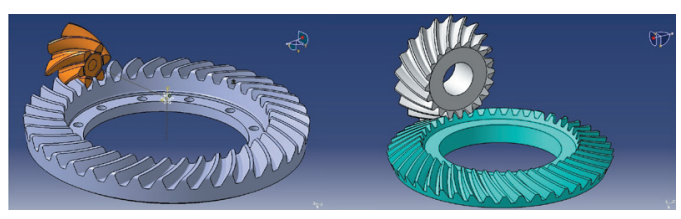

a)

b)

Fig. 1. 3D model of the typical SBG; a) SBG of drive axle of vehicle, and b) SBG of aerospace transmission

To eliminate the restriction of the applied range, reduce processing costs, and improve the universal properties of the special manufacturing system, new manufacturing technologies and design methods of SBGs in universal machines could be investigated. The mathematical model based on geometry characteristics can guide the manufacture of SBGs in universal milling machines. The overview, analysis and comparison of mathematical models are valuable for improving the manufacturing process, machine tool technology, and design method.

This paper reviews almost all related literature on the mathematical model of SBGs and primarily summarizes three methods: the matrix method, the vector method and the geometry method. The matrix method and vector method are based on the special machining processes. The relationship between the manufacturing principle of a particular machine and the mathematical model is illustrated. As the geometry 


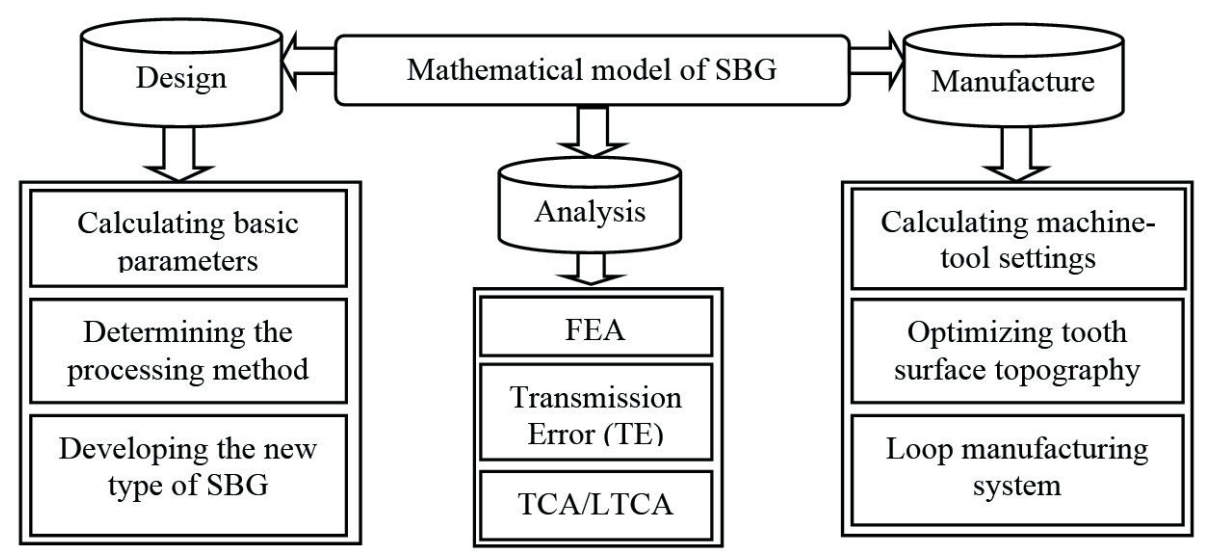

Fig. 2. Application of mathematical model of SBGs

method provides a theoretical model for the new manufacturing method, its development trend is also analysed and discussed.

\section{MATRIX METHOD}

The matrix method is a mathematical tool used to induce spatial transformation in different coordinate systems. Litvin et al. [23] was the first to use the matrix method specifically to build a mathematical model of an SBG.

The conjugation theory of space surfaces [24] and [25], which includes the global and local conjugation theories, is essential to establish a relationship between different surfaces in building the mathematical model of an SBG. The imaginary generating gear, formed by the motion of a rotating cutter blade, maintains line contact with the workpiece during the manufacturing process, in accordance with global conjugation theory and the meshing equation [25]. Based on the local synthesis method [26], the tooth surfaces of the gear and pinion conform with local conjugation theory at the mean contact point; therefore, this theory is used to determine the pinion machine-tool settings of the special machine. The universal conjugation theory of spatial surfaces is shown by Eq. (1) and the meshing equation is shown by Eq. (2).

$$
\begin{gathered}
\left\{\begin{array}{l}
\mathbf{r}_{2}=\mathbf{m}+\mathbf{r}_{1}, \\
\mathbf{n}_{2}=\mathbf{n}_{1}
\end{array}\right. \\
f\left(s_{g}, \theta_{g}, \phi_{1}\right)=\mathbf{n} \cdot \mathbf{v}_{12}=0 .
\end{gathered}
$$

In Eq. (1), $\mathbf{r}_{1}, \mathbf{r}_{2}$ are surface vectors of Surface 1 and surface $2, \mathbf{m}$ is the relative position vector between coordinate systems of Surface 1 and Surface 2. In Eq. (2), $s_{g}, \theta_{g}$ are surface parameters of the cutter head, $\phi_{1}$ is workpiece spindle rotational angle, $\mathbf{n}$ is the normal vector of conjugate plane of gear surface, $\mathbf{v}_{12}$ is the relative velocity between Surfaces 1 and 2 .

Litvin et al. [23] used the matrix method to synthesize and optimize the tooth surface of SBGs. Matrix transformation effectively represents the spatial transformation of the position vector of the cutter blade. However, the meshing equation is decided by the hypothetical conjugate surface instead of the approximate actual non-conjugate tooth surface. Therefore, a gap is created between the mathematical model and the actual SBG tooth surface. Based on differential geometry and the theory of conjugate surfaces, Fong and Stay [27] investigated the mathematical model of SBGs generated by circular plane cutter. In [23], a matrix translation corresponding to the manufacturing process was illustrated, and tooth parameters were solved with the meshing equation. Moreover, a modular arrangement facilitates the conversion of the mathematical model into computer language. Fong and Stay [28] also investigated a mathematical model of the Gleason SBG and derived the undercutting equations through this model, which developed a method used to check the undercutting condition of SBGs. Rao et al. [29] compared a mathematical model created with the matrix method with a geometry model and computed the deviation, which confirmed the high uniformity of the two models. Handschuh [30] described a matrix method to build the SBG mathematical model proposed by Litvin and reviewed advances in applications for analysing SBGs. Clearly, building a mathematical model is the foundation for the thermal and structural analysis of SBGs. For example, Fuentes et al. [31] described how to build an accurate SBG mathematical model for finite element analysis in FORTRAN instead of CAD software. 
Flank modifications primarily include lengthwise crowning, profile modification of tools, and a flank twist from toe to heel. These modifications affect the result of the mathematical model, as shown in Table 1.

To determine the machine-tool settings of the tilted-head cutter, Litvin et al. [32] developed a series of matrix transformations corresponding to the manufacturing process, especially the cutter spindle angle and cutter swivel angle. To build a mathematical model of an SBG manufactured by modified roll, Lin et al. [33] illustrated the kinematic mechanism of a modified roll generation train for manufacturing an SBG and proposed a method to calculate the variable of roll ratio $\eta_{a}$, which is presented by Eq. (3). Fuentes et al. [31] proposed a design method for SBGs manufactured by modified roll. The variable of roll ratio was calculated with the parabolic function of transmission error and TCA output, and this function also provided the variable of roll ratio in terms of design. A CNC hypoid generator facilitates the implementation of nonlinear and higher-order kinematic correction motion to manufacture SBGs. Stadtfeld and Gaiser [34] proposed the theory of Ultimate Motion Graph and Ultimate Motion Concept (UMG/UMC), which is an effective theory for the flank modifications of a $\mathrm{CNC}$ hypoid generator. Fourth-order kinematic correction motion was used to generate the gear geometry with low noise and high strength. However, the relationship between machine-tool settings and flank modifications was not described, because it is difficult to build a mathematical model of SBGs. To reduce transmission error, Simon [35] proposed a method to determine optimal polynomial functions. Fifth-order Polynomial functions were used to determine the relationship between the angle of the cradle rotation and the workpiece. Based on modified machine-tool settings, Fan [36] proposed a mathematical model expressed in terms of the sixth-order polynomial function of the cradle roll increment and angle. This model can be used to simulate the flank modifications manufactured by $\mathrm{CNC}$ hypoid generators.

Table 1. Modified parameters of different flank modifications [34]

\begin{tabular}{ccc}
\hline Flank modifications & Modified parameters & Expression \\
\hline \multirow{2}{*}{ Lengthwise crowning } & Cutter radius & $R_{0}$ \\
\cline { 2 - 3 } & Modified radial motion & $S_{R}=R\left(\phi_{c}\right)$ \\
\hline Profile modification of tool & Tooth profile & $\mathbf{r}_{t}=\mathbf{r}\left(s_{g}, \theta_{g}\right)$ \\
\hline \multirow{2}{*}{$\begin{array}{c}\text { Flank twist from toe to } \\
\text { heel }\end{array}$} & Variable of roll & $\phi_{1}=s\left(\phi_{c}\right)$ \\
\cline { 2 - 3 } & Helical motion & $E_{m}=E\left(\phi_{c}\right)$ \\
\cline { 2 - 3 } & Cutter tilted & $i, j$ \\
\hline
\end{tabular}

In Table $1, R_{0}$ is the cutter radius, $S_{R}$ is the radial setting of the cutter head, $\phi_{c}$ is the cradle rotational angle, $\mathbf{r}_{t}$ is the vector of cutter tool, $E_{m}$ is the blank offset for gear or pinion, $i$ is the cutter swivel angle and $j$ is the cutter spindle angle.

$$
\left\{\begin{array}{l}
R_{a}=\frac{d \phi_{1}}{d \phi_{c}}=1+C \cos \left(\phi_{a}-j\right) / \\
/\left\{a_{0} \cos \left(\phi_{e}-\phi_{a}+j\right)+\right. \\
\left.+r_{u} \cos \left[\frac{r_{u}}{C}\left(\phi_{e}-\phi_{a}+j\right)\right]\right\} \\
\eta_{a}=\frac{T_{i}}{T_{p}} R_{a}
\end{array} .\right.
$$

In Eq. (3), $C$ is the distance between the cradle centre and the rotational centre of the input shaft, $\phi_{a}$ is the angle of rotation of cradle, $a_{0}$ is half the distance between two cam guide ways, $\phi_{e}$ is the angle of rotation of the input shaft, $r_{u}$ is the pitch radius of the generating cams, $T_{i}$ and $T_{p}$ are the tooth numbers of the index interval and pinion, and $R_{a}$ is the instantaneous roll ratio of the cam-follower reciprocator.

Considering the different cutting methods and flank modifications, Fong [37] proposed a universal mathematical model that utilizes the matrix method and facilitates the compilation of object-oriented computer programming. In the future, more details about the simulation of universal face hobbing for SBG can be added to this model.

Face milling and face hobbing are two major cutting systems used to manufacture SBG. The differences between these systems are shown in Table 2.

Table 2. Features of two major cutting systems

\begin{tabular}{lll}
\hline Cutting system & Face milling & Face hobbing \\
\hline $\begin{array}{l}\text { Indexing motion } \\
\text { Lengthwise tooth } \\
\text { curve }\end{array}$ & Single indexing & Timed continuous \\
\hline Tooth depth system & $\begin{array}{l}\text { Uniform or tapered } \\
\text { tooth depth system }\end{array}$ & $\begin{array}{l}\text { Uniform tooth depth } \\
\text { system }\end{array}$ \\
\hline Finish machining & Grinding and lapping & Lapping \\
\hline Machining feature & High tooth accuracy & $\begin{array}{l}\text { High production } \\
\text { efficiency }\end{array}$ \\
\hline
\end{tabular}

As face hobbing combines the timed continuous indexing and generating rolling, it is a more complicated process. The mathematical model is closely related to the generalized kinematic model of face hobbing. Fan [38] proposed a complete modelling of a face-hobbing SBG generated with a Phoenix ${ }^{\circledR} I I$ hypoid generator. This method divided the creation of 
a mathematical model into four sections, disassembled the kinematic motion of the machine, and expressed the machine-tool settings as a function of the cradle increment angle. Shih et al. [39] proposed a universal mathematical model of face-hobbing generation with a wide application range. Vimercati [40] proposed a mathematical model of SBG that can be used to simulate the cutting process of face hobbing, and confirmed its high accuracy through an actual case. Compared with that of face milling, the complexity of the mathematical model of a face-hobbing SBG is primarily reflected in the mathematical model of the cutter blade and the relative motion between the imaginary generating gear and workpiece.

The traditional cradle-type hypoid generator is being gradually replaced by the CNC hypoid generator. The machine-tool settings of the CNC hypoid generator are transformed from those of the virtual traditional cradle-type universal hypoid generator, and the mathematical model is also built by the traditional method. Shih and Fong [41] proposed a mathematical model of the Cartesian-type hypoid generator. The machine-tool settings of three rectilinear motions and three rotational motions in the Cartesian system were converted from a previously proposed universal hypoid generator [39]. Simon [42] developed an algorithm to ensure the relationship between the machine-tool settings of the CNC hypoid generator and those of the cradle-type generator. In the future, a method to directly build the mathematical model of SBG generated by CNC hypoid generator can be investigated.

As the tooth surface of an SBG is the motion trajectory of the cutter blade, the mathematical model of the cutter blade is of key importance. A straight cutting blade is often used to cut the workpiece during face milling [27], [28], [30] and [31]. To obtain high strength and low noise, however, a parabolic profile blade is used to generate the SBG. Litvin et al. [43] provided equations for three shapes of blade profile and confirmed the satisfactory transmission performance of SBG generated by a parabolic profile blade. The mathematical model of the face-hobbing cutter blade is more complex. Fan [38], Vimercati [40], and Shih and Fong [41] provided the matrix equation of the position vector of the cutter blade in face hobbing generation. Vimercati [40] also analysed an actual face-hobbing cutter head and presented a complex equation of a curved blade with Toprem. The equation was obtained by analysing the complex cutter blade, which included the bottom, fillet, Toprem and curved blade. However, a more accurate model of the tooth surface is required to analyse genuine cutter geometric models. Xie [44] described a genuine facemilling cutter geometric model with the parameters of blade angle, rake angle and relief angle. In simplified cutter geometry, the side and circular cutting edges of the blade are expressed on the normal plane. In [44], the blade rake plane was used to replace the normal plane, which matches real cutter geometry. Obviously, this research provided a method to improve the accuracy of the mathematical model of the facemilling cutter blade, and more studies are expected to extend to the face-hobbing cutter geometric model.

The mathematical model based on the matrix method has been developed into basic technology for computer-integrated methods to design, manufacture and analyse SBGs in special hypoid generation. As the mathematical model follows the manufacturing principle of special machine, it closely matches the actual gear. Although complicated, the matrix method is a clear spatial transformation process that yields a universal mathematical model adopted by most existing cutting systems. However, this method can be used only in special hypoid generation. Furthermore, the nonlinear meshing equation is difficult to solve, especially in the tooth root segment. The formation of the generated surface equations and their derivatives lead to inefficiency in solving the computer programming and contact algorithms.

\section{VECTOR METHOD}

The vector method, proposed by Di Puccio et al. [45], is an alternative formulation of gear theory; this formulation of the mathematical model of SBGs is clearer and more compact. The advantage of the vector method is that only vector formulation is used to express the surface model. The spatial transformation of the vector method conforms with the principle of rotating vectors. The vector method also avoids using the reference coordinate system in building mathematical models of SBGs.

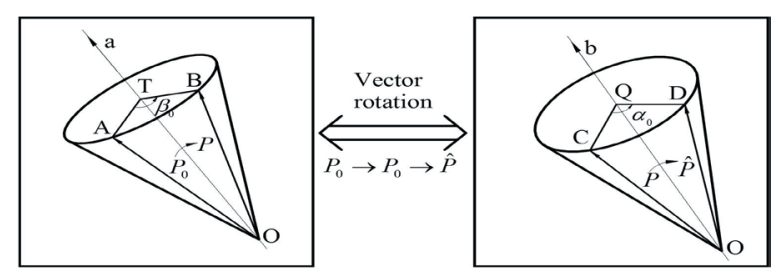

Fig. 3. Vector rotation of position vector

The vector is rotated to translate the cutter blade spatially, and vector rotation around a mobile axis can simulate all translation processes in one expression. 
According to Fig. 3, the vector $\mathbf{p}$ is the rotation of the position vector $\mathbf{p}_{0}$ around the unit vector $\mathbf{a}$ by an angle $\beta_{0}$, and the vector $\hat{\mathbf{p}}$ can be obtained by rotating position vector $\mathbf{p}$ around the unit vector $\mathbf{b}$ by an angle $\alpha_{0}$. The vector translation process can be expressed as Eq. (4) [45].

$$
\left\{\begin{array}{l}
\mathbf{p}=R\left(\mathbf{p}_{0}, \mathbf{a}, \beta_{0}\right) \\
\hat{\mathbf{p}}=R\left(\mathbf{p}, \mathbf{b}, \alpha_{0}\right)=R\left(R\left(\mathbf{p}_{0}, \mathbf{a}, \beta_{0}\right), \mathbf{b}, \alpha_{0}\right)
\end{array}\right.
$$

The derivative of the vector method with respect to the surface parameters is a simplified expression for solving the meshing equation. Eq. (5) [45] shows that the derivatives of the tooth surface parameters are compact.

$$
\left\{\begin{array}{l}
\hat{\mathbf{P}}_{, s_{g}}=R\left(\mathbf{p}_{s_{g}}\left(s_{g}, \theta_{g}\right), \mathbf{a}, \alpha\left(\phi_{c}\right)\right) \\
\hat{\mathbf{P}}_{\theta_{g}}=R\left(\mathbf{p}_{\theta_{g}}\left(s_{g}, \theta_{g}\right), \mathbf{a}, \alpha\left(\phi_{c}\right)\right) \\
\hat{\mathbf{P}}_{, \phi_{c}}=R\left(\mathbf{p}_{\phi_{c}}\left(s_{g}, \theta_{g}, \phi_{c}\right), \mathbf{a}, \alpha\left(\phi_{c}\right)\right)+\alpha \mathbf{a} \times \hat{\mathbf{p}}\left(s_{g}, \theta_{g}, \phi_{c}\right)
\end{array} .\right.
$$

The meshing equation is represented by vector formation and requires no reference system. To avoid the application of a kinematic concept and relative differentiation, the meshing equation can be expressed as Eq. (6) [45].

$$
\begin{aligned}
& f\left(s_{g}, \theta, \phi\right)= \\
& =\left[\mathbf{p}_{e, s_{g}}\left(s_{g}, \theta_{g}\right) \mathbf{p}_{e, \theta_{g}}\left(s_{g}, \theta_{g}\right) \mathbf{h}_{e}\left(s_{g}, \theta_{g}, \eta_{a} \phi_{c}\right)\right]= \\
& =\mathbf{m}_{e}\left(s_{g}, \theta_{g}\right) \times \mathbf{h}_{e}\left(s_{g}, \theta_{g}, \eta_{a} \phi_{c}\right)=0 .
\end{aligned}
$$

Di Puccio et al. [45] described the relative concept and formula derivation of the vector method in gear theory, analysed its application in building a mathematical model of an SBG, and described the characteristics of vector method through a numerical example of aerospace transmission application. However, this application is involved in a simple facemilling process of the traditional cradle-type special generator. A complementary description of the vector method was proposed by Di Puccio et al. [46]. The principle of vector rotation around a mobile axis was proposed to express the complex spatial translation of the position vector of the cutter blade; this principle might even be used in supplemental spatial motions of the modern free-form cutting machine. A numerical example illustrates the convenience of constructing a mathematical model of SBGs. Further research could be conducted to build universal mathematical models by vector method.
The curvature of SBG tooth surfaces is analysed to evaluate their geometric features, mechanical properties, and physical characteristics. Di Puccio et al. [47] compared the different characteristics of Litvin's approach [48], Chen's approach [49], Wu and Luo's approach [50], and the vector method for curvature analysis. In [47], vectors and tensors were introduced to analyse the curvature in vector method, and curvature tensors were used to simplify the analysis. Puccio et al. [51] used the proposed vector method to analyse curvature. The vector method can avoid using the reference system and provides explicit formulas to analyse curvature. Indeed, the vector method is a more compact and computationally efficient method for analysing curvature than other methods.

The vector method and matrix method are applied to simulate the similar machining processes and actual transformation path of the cutting blade, as shown in Fig. 4. However, they have different formulations in building mathematical models, as shown in Table 3 [37] and [46]. By avoiding the reference system, the vector method for expressing tooth surface is more compact and cleaner. Obviously, the vector method is an alternative formulation for the mathematical modelling of SBGs, and it facilitates the simplification of computer programming and the improvement of computational efficiency. Thus, the application range of the vector method could be extended.

In Fig. 4, $q$ is the instalment angle for the cutter head, $\gamma_{m}$ is the machine root angle, $x_{b}$ is the sliding base for gear or pinion, $x_{p}$ is the increment of machine centre to back.

In Table $3, R_{g}$ is the cutter head point radius, $\alpha_{g}$ is the blade angle of the cutter head, $\eta_{a}$ is the instantaneous roll ratio, $\left[\mathbf{L}_{1 t}\left(\phi_{c}\right)\right],\left[\mathbf{L}_{q}\right]$ is the $3 \times 3$ homogeneous transformation matrix, $\left[\mathbf{M}_{i j}\right]$ is the $4 \times 4$ homogeneous transformation matrix from coordinate systems $S_{j}$ to $S_{i}$.

\section{GEOMETRY METHOD}

Based on the principle of the geometry method, the geometry model of an SBG is determined by basic geometric parameters instead of machine-tool settings. In fact, the geometry model is a theoretical model, and it emphasizes the guidance for manufacturing SBG. Geometric characteristics include tooth profile and centreline. The tooth profile primarily includes the spherical involute, approximate spherical involute, and circuit arc. Many spirals, such as the logarithmic spiral, circular cut spiral and involute spiral, can serve as the tooth centreline. 


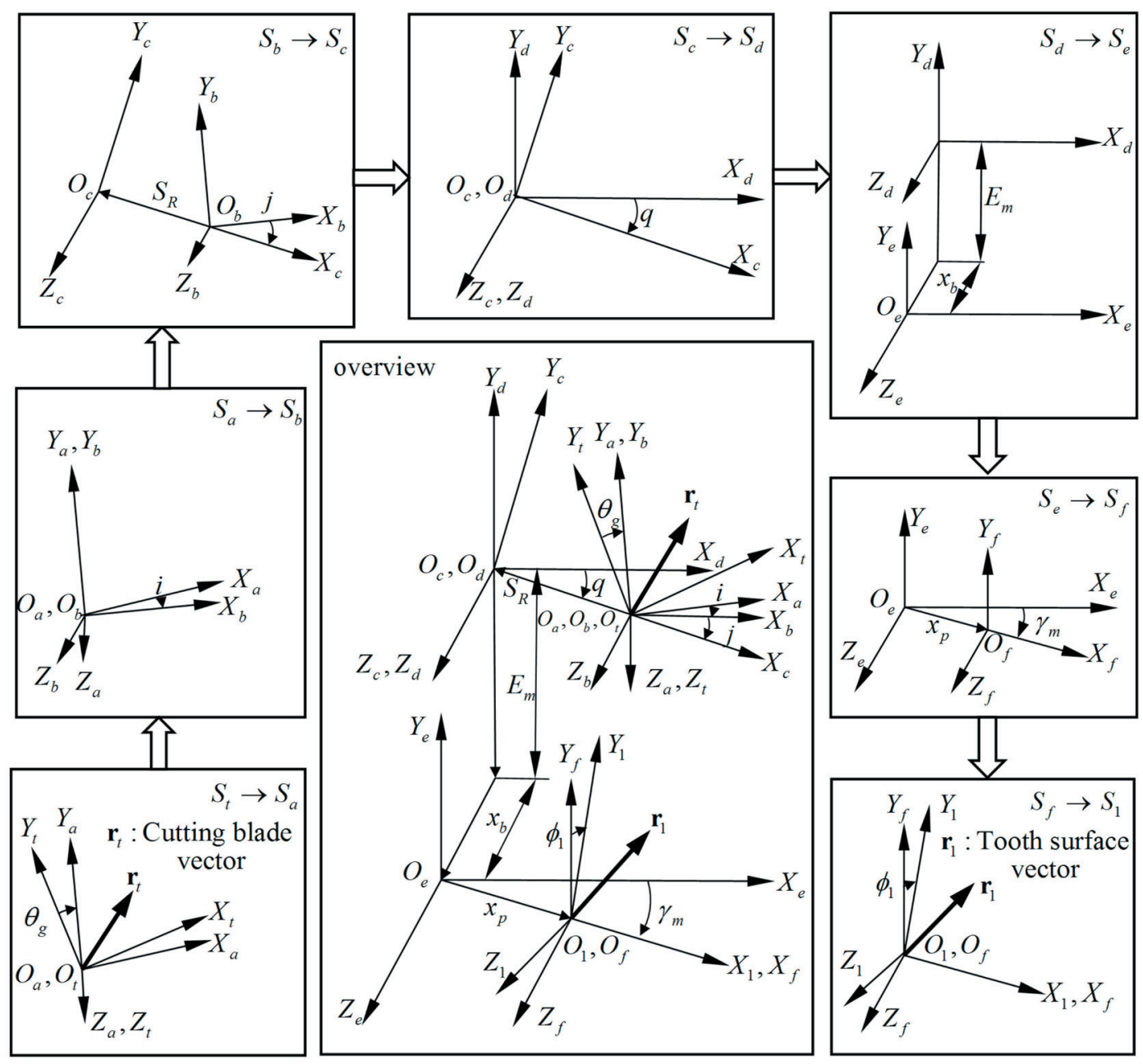

Fig. 4. Transformation of cutting blade vector in machining process [37]

Table 3. Comparison of matrix method and vector method [37] and [46]

\begin{tabular}{lcc}
\hline $\begin{array}{l}\text { Mathematical } \\
\text { model }\end{array}$ & \multicolumn{1}{c}{ Vector method } & Matrix method \\
\hline $\begin{array}{l}\text { Position } \\
\text { vector of } \\
\text { cutter head }\end{array}$ & $\mathbf{p}_{\mathbf{e}}\left(s_{g}, \theta_{g}\right)=\left[\begin{array}{c}\left(R_{g} \pm s_{g} \sin \alpha_{g}\right) \cos \theta_{g} \\
\left(R_{g} \pm s_{g} \sin \alpha_{g}\right) \sin \theta_{g} \\
-s_{g} \cos \alpha_{g}\end{array}\right]$ & $\mathbf{r}_{\mathbf{t}}\left(s_{g}, \theta_{g}\right)=\left[\begin{array}{l}\left(R_{g} \pm s_{g} \sin \alpha_{g}\right) \cos \theta_{g} \\
\left(R_{g} \pm s_{g} \sin \alpha_{g}\right) \sin \theta_{g} \\
-s_{g} \cos \alpha_{g}\end{array}\right]$ \\
\hline $\begin{array}{l}\text { Meshing } \\
\text { equation }\end{array}$ & $f\left(s_{g}, \theta_{g}, \phi_{c}\right)=\mathbf{m}_{e}\left(s_{g}, \theta_{g}\right) \times \mathbf{h}_{e}\left(s_{g}, \theta_{g}, \eta_{a} \phi_{c}\right)=0$ & $f\left(s_{g}, \theta_{g}, \phi_{c}\right)=\mathbf{n}_{1} \times \mathbf{v}_{12}=0$ \\
\hline $\begin{array}{l}\text { Spatial } \\
\text { translation }\end{array}$ & $p_{g}\left(s_{g}, \theta_{g}, \phi_{c}\right)=R\left(R\left(R\left(R\left(\mathbf{p}_{e}\left(s_{g}, \theta_{g}\right)+\right.\right.\right.\right.$ & {$\left[\mathbf{M}_{1 t}\right]=\left[\mathbf{M}_{1 f}\right] \times\left[\mathbf{M}_{f e}\right] \times\left[\mathbf{M}_{e d}\right] \times$} \\
\hline $\left.\left.\mathbf{e}\left(\phi_{c}\right), \mathbf{r}_{a}\left(\phi_{c}\right), \varepsilon_{a}\left(\phi_{c}\right)\right), \mathbf{a}\left(\phi_{c}\right), \psi\left(\phi_{c}\right)\right)-$ & $\times\left[\mathbf{M}_{d c}\right] \times\left[\mathbf{M}_{c b}\right] \times\left[\mathbf{M}_{b a}\right] \times\left[\mathbf{M}_{a t}\right]$ \\
\hline $\begin{array}{l}\text { Equation of } \\
\text { tooth surface }\end{array}$ & $\left.\left.-\mathbf{d}\left(\phi_{c}\right), \mathbf{b}\left(\phi_{c}\right),-\varphi\left(\phi_{c}\right)\right), \mathbf{r}_{b}\left(\phi_{c}\right),-\varepsilon_{b}\left(\phi_{c}\right)\right)$ & $\mathbf{r}\left(s_{g}, \theta_{g}, \phi_{c}\right)=\left[\mathbf{L}_{1 t}\left(\phi_{c}\right)\right] \cdot \mathbf{r}_{t}\left(s_{g}, \theta_{g}\right)$ \\
\hline
\end{tabular}




\subsection{Logarithmic Spiral Bevel Gear}

The logarithmic spiral bevel gear (LSBG) provides excellent transmission performance with a constant spiral angle. Huston and Coy [52] provided the geometric characteristics and model of LSBG and proposed the concept of the "ideal SBG". Tsai and Chin [53] investigated the tooth surface geometry of LSBG and provided an equation of logarithmic spiral on pitch plane, which is presented in Eq. (7). The geometry model of LSBG can be obtained with Eq. (8).

$$
r=R_{m} \cdot e^{\cot \psi \cdot \bar{\theta}} .
$$

In Eq. (7), $r$ is the radial distance on the pitch plane, $\bar{\theta}$ is the polar angle on the pitch plane, $r=R_{m}$ when $\bar{\theta}=0, \psi_{m}$ is the mid-spiral angle, as shown in Fig. 5.

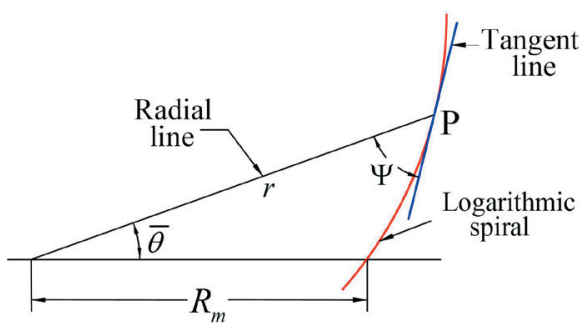

Fig. 5. Logarithmic spiral on pitch plane [53]

However, the consistency of the LSBG tooth centreline between the manufactured gear model and the geometry model is a key issue in the manufacturing process. Li et al. [54] investigated the meshing equation and the spatial relationship between the cutter blade and workpiece. This investigation is a theoretical exploration of the processing technology of LSBGs, and further research on its application in an actual manufacturing process can be conducted. Ju [55] developed a strategy to control the tool path of a finger-milling cutter of five-axis universal milling in manufacturing processes. A geometry model was built in Pro/e and translated into NC code in UG CAM. This method provides guidance for manufacturing LSBG. However, the accuracy of the generated LSBG still could be improved. Alves et al. [56] proposed a reliable design and manufacturing method of a universal five-axis milling machine, including a geometry analysis of the tooth surface, LTCA, and tooth modifications. The accuracy of the generated LSBG was validated via surface measurements.

In Eq. (8), $X_{t}, Y_{t}$ and $Z_{t}$ are the coordinate of the tooth surface, $\alpha$ is the root cone angle, $\beta$ is the involute generating angle, and $\theta$ is the polar angle on $X-Y$ plane, as shown in Fig. 6.

$$
\left\{\begin{aligned}
X_{t}= & r \sin \alpha \cos (\theta+\beta)\left(1-\frac{\beta^{2}}{2} \sin ^{2} \alpha\right)+ \\
& +r \beta \sin \alpha \sin (\theta+\beta) \sqrt{1-\frac{\beta^{2}}{4} \sin ^{2} \alpha} \\
Y_{t}= & r \sin \alpha \sin (\theta+\beta)\left(1-\frac{\beta^{2}}{2} \sin ^{2} \alpha\right)- \\
& -r \beta \sin \alpha \cos (\theta+\beta) \sqrt{1-\frac{\beta^{2}}{4} \sin ^{2} \alpha} \\
Z_{t}= & r \cos \alpha\left(1-\frac{\beta^{2}}{2} \sin ^{2} \alpha\right)
\end{aligned}\right.
$$

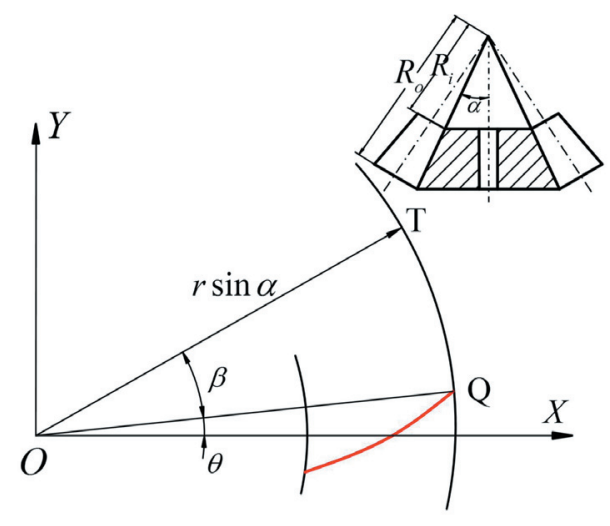

Fig. 6. Spiral tooth centreline on X-Y plane [53]

Duan et al. [57] proposed a theory of loxodromic normal circular-arc spiral bevel gear (LCBG), which is a typical LSBG. The tooth profile is a circular arc; the tooth alignment curve is a logarithmic spiral, and the centre of the tooth profile is located on the tooth alignment curve. The mathematical expression of the tooth profile and tooth alignment curve was proposed. The manufacturing process was investigated by Duan et al. [58], including the parameters of the form milling cutter, contact conditions, and relative motion relationship between the form milling cutter and the workpiece, which illustrated excellent machinability in the universal four-axis machining centre. Duan et al. [59] developed a complete process of designing and manufacturing LCBGs, introduced the basic idea of the mathematical model of LCBGs, and investigated the determination method of the tool path and tooth alignment curve. The manufacturing programming of LCBGs was used to achieve geometric characteristics, which provided a new generation theory of manufacturing LCBGs. 
In short, an LSBG is an excellent transmission component, in theory. However, the manufacturing techniques of LSBGs are still to be improved. The challenge in manufacturing LSBGs is to achieve its geometric characteristics, especially the tooth centreline.

\subsection{Circuit Cut Spiral Bevel Gear}

Because the tooth centreline is a circuit spiral, a "circuit cut" SBG is conveniently manufactured by a rotary cutter blade and other special tools, which is the manufacturing principle adopted by Gleason. Tsai and Chin [53] proposed an equation for the tooth centreline on a pitch plane, as described in Eq. (9). The geometry model was built with a spherical involute and circuit spiral, and an actual Gleason SBG was used to verify its accuracy.

In Eq. (9), $R_{c}$ is the cutter radius. Point $\mathrm{O}$ is the gear centre, and Point $\mathrm{C}$ is the cutter centre, as shown in Fig. 7.

Al-Daccak et al. [60] introduced a method to build a model of a circuit-cut SBG by using an exact spherical involute, which was defined as the curve on a sphere. The spherical involute was generated by rolling the circuit plane over the base cone, and a solid model of SBG can be created by twisting spherical involute along the tooth centreline.

Tsai and Chin [53] proposed the approximate spherical involute, which is obtained via a rectangle tangent plane rolling over the base cone. Shunmugam et al. [61] investigated a mathematical model with an exact spherical involute, which is obtained via a circuit tangent plane rolling over the base cone, as shown in Table 4. The ideal model is formed by the trace line on the tangent plane rolling over the base cone. Eq. (10) shows that the points of the tooth surface can be achieved by changing the value of the parameters $\alpha_{1}$, $\beta_{1}$ and $v$.

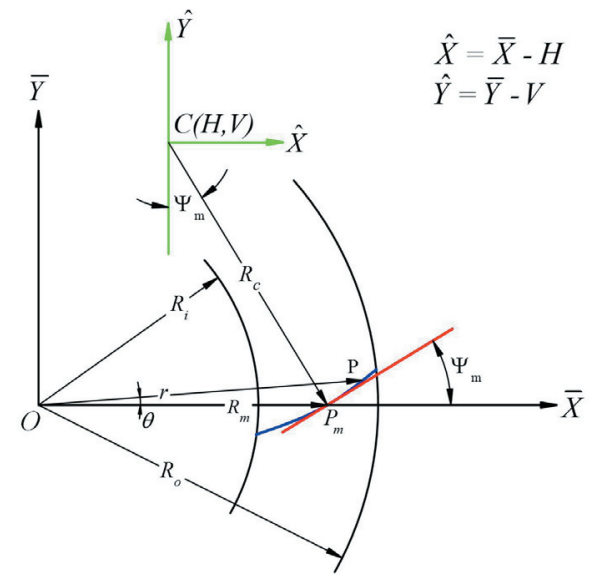

Fig. 7. Top view of circular-cut tooth centreline on pitch plane [53]

$$
\begin{gathered}
\left(X-R_{m}+R_{c} \sin \psi_{m}\right)^{2}+\left(Y-R_{c} \cos \psi_{m}\right)^{2}=R_{c}^{2} . \\
\left\{\begin{array}{c}
x=r_{0} \cos \left(\beta \sin \alpha_{0}-v\right) \sin \alpha_{0} \cos \beta+ \\
\quad+r_{0} \sin \left(\beta \sin \alpha_{0}-v\right) \sin \beta \\
y=r_{0} \cos \left(\beta \sin \alpha_{0}-v\right) \sin \alpha_{0} \sin \beta- \\
\quad-r_{0} \sin \left(\beta \sin \alpha_{0}-v\right) \cos \beta \\
z=r_{0} \cos \left(\beta \sin \alpha_{0}-v\right) \cos \alpha_{0}
\end{array}\right.
\end{gathered}
$$

Table 4. Comparison of two spherical involutes [53] and [61]

\begin{tabular}{ll} 
Exproximate spherical involute \\
Equation \\
\hline Difference
\end{tabular}


In Table 4 and Eq. (10), $X_{p}, Y_{p}, Z_{p}$ are the coordinates of typical point $\mathrm{P}$ of the spherical involute. $r_{0}$ is the radius of the sphere in case of spherical involute (the cone distance), $\beta$ is the rotation angle of the tangent plane over base cone, $\alpha_{0}$ is the base cone angle, and $v$ is the polar angle of a point on the circular arc.

Suh et al. [62] proposed a sculpted surface machining method for manufacturing SBGs with a three-axis CNC milling machine interfaced with a rotary table. The bi-parametric surface model can be derived via spatial translation with geometric characteristics. The CC point was sampled from a bi-parametric surface model, and a CC-parametric scheme was applied to control the tool path. Although the machining time is not ideal, the broad cutting range and generating a special type of gear can be implemented, which shows potential applications of this method. Suh et al. [63] investigated the method of manufacturing SBGs with a crown. The crown model was built via crown functions in longitudinal and involute curve directions. This geometry model was implemented in the GearCAM system with fouraxis $\mathrm{CN}$ milling, which verified the validity of this manufacturing method.

Tsai and Hsu [64] investigated a manufacturing and design method for the new point contact-type SBG. The mathematical model was built using tooth profiles and circular-arc contact paths.

Safavi et al. [65] invented the form milling method of manufacturing SBGs with an additional PLC module. Commercial software was used to build a CAD model, simulate the manufacturing process, and generate tool paths. This method provides a more automatic and simple process technology for manufacturing SBGs. However, the application of commercial software based on the specific manufacturing principle requires further research to verify the precision of generated gear.

Zhang et al. [66] developed a generating method for SBGs with spherical involute tooth curves. The tooth surface model was formed by the relative rolling motion of the tracing line on the tangent plane. The motion of the cutting edge of the cutter simulated the actual tracing line rolling on the base cone. The same tracing line was applied to cut a pair of gears, and the pinion ensures stable and proper meshing conditions. The kinematic velocity and processing principle were used to illustrate the control theory of the CNC machine. The construction of the machine, as well as motion control, is simple and not subject to restriction of gear size. This research also analysed the straight tracing line. Additional research can focus on other types of tracing lines, such as the logarithmic spiral, circuit arc spiral, and involute spiral. To confirm its excellent transmission performance, the research on contact characteristics of SBGs generated by this method should be conducted.

The mathematical model of the circuit arc SBG and manufacturing method based on its geometric characteristics are reviewed in this section. As the tooth centreline can easily be controlled, a circuit arc SBG has a wider application range. In particular, Gleason's manufacturing principle is a typical application of the geometry model.

\subsection{Involute Spiral Bevel Gear}

The involute spiral bevel gear is another SBG type, which is a theoretical model of Klingeinberg and Oerlikon's method. Tsai and Chin [53] formulated the equation of an involute spiral on a tangent plane. Additional research focusing on the contact characteristics and transmission performance of this gear type can be conducted. The current application is in Klingeinberg and Oerlikon's gear manufacturing method. However, the mathematical model of involute SBG could be applied to more situations generated by the universal milling machine. The tool path is also a challenge in implementing new manufacturing methods.

As analysed from sections 3.1 to 3.3 , the process of building a mathematical model of an SBG can be simplified with the geometry method, which avoids the difficulties of solving the meshing equation and spatial transformation. The geometry model can be easily built using CAD software; based on the geometry model, several manufacturing methods have already been developed. The geometry method provides a theoretical model and can be used to explain the manufacturing principle.

\section{CONCLUSIONS}

The development of CAD/CAM technology has made mathematical models indispensable in the design and manufacturing of SBGs. To analyse the process of building a mathematical model and the application of a mathematical model in design and manufacture, this paper reviews the methods of building mathematical models of SBGs, including the matrix method, vector method, and geometry method.

The matrix method and vector method are special methods based on the special machining principle of SBGs. The mathematical models are derived from actual machine-tool settings and are thus consistent 
with the actual manufacturing tooth surfaces. These two methods have a close relationship with the manufacturing process; this relationship benefits the application of the loop manufacturing system. Coordinate transformation in matrix representation can produce a clear spatial translation process. However, matrix expression is complicated, and converting it into computer language is difficult. The vector method presents a more compact and clearer formulation and does not need any coordinate system in vector rotation. Although the expression forms of spatial transformation are different, the theory and application range of these two methods are similar. Solving the meshing equation of both methods is complicated, especially in the tooth root segment.

The geometry model places more emphasis on the theoretical model, which is used to develop new manufacturing principles. To research new types of SBGs, the geometry model could be built primarily for the presentation of a design idea.

Several research fields, which could be further targeted, include:

(1) The matrix and vector methods are modelling methods based on manufacturing principles. Further research may illustrate more details of new manufacturing methods, including the machine motion, cutter geometric model, and the relationship between the cutter blade and workpiece, which will benefit the application of building a mathematical model of SBGs by these two methods.

(2) The geometry method is proposed as a "theoretical model", and it is a breakthrough in the study of new SBG theories. However, the rationality of current methods of controlling the tool path with commercial software will be further confirmed. Thus, more research on building the relationship between geometric features and the machining process could be conducted. Future studies on the application of the geometry model are likely to consider the shapes of the milling cutter and the tool path. In practice, the disk milling cutter is an efficient tool, but the tool path is difficult to control; the finger milling cutter is easy to control, but its productivity can be improved. Further research on the application of the geometry model can focus on new process technology, such as the forging manufacturing technique, roll forming, and powder forming technology.

(3) The manufacture of large-scale SBGs is a challenge because of the high demand for control accuracy and large machining distortion. The application of the mathematical model may provide more reliable and effective methods for manufacturing large-scale SBGs.

(4) The transmission performance and contact characteristics are different in various types of SBGs. The evaluation criterion can be built by analysis methods, such as FEM, TCA, and LTCA. The evaluation results can be used to guide the application of different types of SBGs in power transmission.

\section{ACKNOWLEDGEMENTS}

The authors acknowledge the financial support from National Natural Science Foundation of China (No. 51075179), the Chinese Government's Executive Program for Exploring the Deep Interior Beneath the Chinese Continent - Instrumentation Development for Deep Continental Scientific Drilling (Sinoprobe-09-05) and Scientific Frontier and Interdisciplinary Merit Aid Projects of Jilin University, China (No. 2013ZY08).

\section{REFERENCES}

[1] Sekercioglu, T., Kovan, V. (2007). Pitting failure of truck spiral bevel gear. Engineering Failure Analysis, vol. 14, no. 4, p. 614-619, DOI:10.1016/j. engfailanal.2006.03.002.

[2] Polubinski, J., Ali, A. (2010). Simulation analysis of commercial truck spiral bevel gear process. International Journal of Modelling in Operations Management, vol. 1, no. 2, p. 179-208, DOI:10.1504/ IJMOM.2010.038149.

[3] Lewicki, D.G., Handschuh, R.F., Henry, Z.S., Litvin, F.L. (1994). Low-noise, High-strength, spiralbevel gears for helicopter transmissions. Journal of Propulsion and Power, vol. 10, no. 3, p. 356-361, DOI:10.2514/3.23764.

[4] Handschuh, R.F., Bibel, G.D. (1999). Experimental and analytical study of aerospace spiral bevel gear tooth fillet stresses. Journal of Mechanical Design, vol. 121, no. 4, p. 565-572, DOI:10.1115/1.2829500.

[5] Fong, Z.H., Tsay, B.C.B. (1991). A study on the tooth geometry and cutting machine mechanisms of spiral bevel gears. Journal of Mechanical Design, vol. 113, no. 3, p. 346-351, DOI:10.1115/1.2912788.

[6] Xing, Y., Qin, S.F., Wang, T.Y., Cheng, K. (2011). Subdivision surface modeling for spiral bevel gear manufacturing. International Journal of Advanced Manufacturing Technology, vol. 53, no. 1-4, p. 63-70, DOI:10.1007/s00170-010-2813-1.

[7] Ma, N., Xu, W.J, Wang, X.Y. Wei, Z.F., Pang, G.B. (2011). Prediction method for surface finishing of spiral bevel gear tooth based on least square support vector machine. Journal of Central South University of 
Technology, vol. 18, no. 3, p. 685-689, DOI:10.1007/ s11771-011-0748-9.

[8] Litvin, F.L., Fuentes, A., Demenego, A., Vecchiato, D., Fan, Q. (2001). New developments in the design and generation of gear drives. Proceedings of the Institution of Mechanical Engineers, Part C: Journal of Mechanical Engineering Science, vol. 215, no. 7, p. 747-757, DOI:10.1243/0954406011524117.

[9] Li, J.G., Mao, S.M., He, J.L., Wu, X.T. (2006). Optimization of pinion roughing of spiral bevel and hypoid gear. Proceedings of the Institution of Mechanical Engineers, Part C: Journal of Mechanical Engineering Science, vol. 220, no. 4, p. 483-488, DOI:10.1243/09544062C04105.

[10] Liu, G.L., Chang, K., Liu, Z.L. (2013). Reverse engineering of machine-tool settings with modified roll for spiral bevel pinions. Chinese Journal of Mechanical Engineering, vol. 26, no. 3, p. 573-584, DOI:10.3901/ CJME.2013.03.573.

[11] Tang, J.Y., Hu, Z.H., Wu, L.J., Chen, S.Y. (2013). Effect of static transmission error on dynamic responses of spiral bevel gears. Journal of Central South University of Technology, vol. 20, no. 3, p. 640-647, DOI:10.1007/ s11771-013-1530-y.

[12] Simon, V. (2013). Design of face-hobbed spiral bevel gears with reduced maximum tooth contact pressure and transmission errors. Chinese Journal of Aeronautics, vol. 26, no. 3, p. 777-790, DOI:10.1016/j. cja.2013.05.005.

[13] Mermoza, E., Astoula, J., Sartor, M., Linares, J.M., Bernard, A. (2013). A new methodology to optimize spiral bevel gear topography. CIRP Annals Manufacturing Technology, vol. 62, no. 1, p. 119-122, DOI:10.1016/j.cirp.2013.03.067.

[14] Artonia, A., Gabiccinia, M., Kolivandb, M. (2013). Ease-off based compensation of tooth surface deviations for spiral bevel and hypoid gears: Only the pinion needs corrections. Mechanism and Machine Theory, vol. 61, p. 84-101, DOI:10.1016/j. mechmachtheory.2012.10.005.

[15] Artoni, A., Gabiccini, M., Guiggiani, M., Kahraman, A. (2011). Multi-objective ease-off optimization of hypoid gears for their efficiency, noise, and durability performances. Journal of Mechanical Design, vol. 133, no. 12, p. 121007-1-121007-9, DOI:10.1115/1.4005234.

[16] Hotait, M.A., Kahraman, A., Nishino, T. (2011). An investigation of root stresses of hypoid gears with misalignments. Journal of Mechanical Design, vol. 133, no. 7, p. 071006-1-071006-9, DOI:10.1115/1.4004224.

[17] Ural, A., Heber, G., Wawrzynek, P.A., Ingraffea, A.R., Lewicki, D.G., Neto, J.B.C. (2005). Three-dimensional, parallel, finite element simulation of fatigue crack growth in a spiral bevel pinion gear. Engineering Fracture Mechanics, vol. 72, no. 8, p. 1148-1170, DOI:10.1016/j.engfracmech.2004.08.004.

[18] Hua, X., Lim, T.C., Peng, T., Wali, W.E. (2012). Dynamic analysis of spiral bevel geared rotor systems applying finite elements and enhanced lumped parameters. International Journal of Automotive Technology, vol. 13, no. 1, p. 97-107, DOI:10.1007/ s12239-012-0009-4.

[19] Kawasaki, K., Tsuji, I. (2010). Analytical and experimental tooth contact pattern of large-sized spiral bevel gears in cyclo-palloid system. Journal of Mechanical Design, vol. 132, no. 4, p. 041004-1041004-8, DOI:10.1115/1.4001348.

[20] Astoul, J., Geneix, J., Mermoz, E., Sartor M. (2013). A simple and robust method for spiral bevel gear generation and tooth contact analysis. International Journal on Interactive Design and Manufacturing, vol. 7, no. 1, p. 37-49, DOI:10.1007/s12008-012-0163-y.

[21] Wang, P.Y., Fan, S.C., Huang, Z.G. (2011). Spiral bevel gear dynamic contact and tooth impact analysis. Journal of Mechanical Design, vol. 133, no. 8, p. 084501-1-084501-6, DOI:10.1115/1.4004544.

[22] Litvin, F.L., Coy, J.J., Tsung, W.J., Heine, C. (1987). Method for generation of spiral bevel gears with conjugate gear tooth surfaces. Journal of Mechanisms, Transmissions and Automation in Design, vol. 109, no. 2, p. 163-170, DOI:10.1115/1.3267431.

[23] Litvin, F.L., Rahman, P., Goldrich, R.N. (1982). Mathematical models for the synthesis and optimization of spiral bevel gear tooth surfaces. NASA CR-3553.

[24] Litvin, F.L. (1989). Theory of gearing. NASA Reference Publication-1212, Washington DC.

[25] Litvin, F.L. (1994). Gear Geometry and Applied Theory. PTR Prentice-Hall, Englewood Cliffs.

[26] Litvin, F.L., Zhang, Y. (1991). Local Synthesis and Tooth Contact Analysis of Face-Milled Spiral Bevel Gears. NASA Technical Report 90-C-028, Washington DC.

[27] Fong, Z.H., Tsay, B.C. (1991). A mathematical model for tooth geometry of circular-cut spiral bevel gears. Journal of Mechanical Design, vol. 113, no. 2, p. 174181, DOI:10.1115/1.2912766.

[28] Fong, Z.H., Tsay, C.B. (1992). The undercutting of circular-cut spiral bevel gears. Journal of Mechanical Design, vol. 114, no. 2, p. 317-325, DOI:10.1115/1.2916949.

[29] Rao, B.S., Shunmugam, M.S., Jayaprakash, V. (1994). Mathematical model for generation of spiral bevel gears. Journal of Materials and Processing Technology, vol. 44, no. 2, p. 775-777, DOI:10.1016/09240136(94)90446-4.

[30] Handschuh, R.F. (1997). Recentadvances in the analysis of spiral bevel gears. MTM'97 International Conference on Mechanical Transmissions and Mechanisms, paper no. NASA TM-107391, p. 1-8.

[31] Fuentes, A., Mullins, B.R., Handschuh, R.F., Woods, R., Litvin, F.L. (2002). Design and stress analysis of low-noise adjusted bearing contact spiral bevel gears. Journal of Mechanical Design, vol. 124, no. 3, p. 524532, DOI:10.1115/1.1481364.

[32] Litvin, F.L., Heine, C., Zhang, Y. (1988). Determination of settings of a tilted head cutter for generation of hypoid and spiral bevel gears. Journal of Mechanisms, 
Transmissions and Automation in Design, vol. 110, no. 4, p. 495-500, DOI:10.1115/1.3258950.

[33] Lin, C.Y., Tsay, C.B., Fong, Z.H. (1997). Mathematical model of spiral bevel and hypoid gears manufactured by the modified roll method. Mechanism and Machine Theory, vol. 32, no. 2, p. 121-136, DOI:10.1016/S0094114X(96)00043-2.

[34] Stadtfeld, H.J., Gaiser, U. (2000). The ultimate motion graph. Journal of Mechanical Design, vol. 122, no. 3, p. 317-322, DOI:10.1115/1.1286124.

[35] Simon, V.V. (2009). Design and manufacture of spiral bevel gears with reduced transmission errors. Journal of Mechanical Design, vol. 131, no. 4, p. 041007-1041007-11, DOI:10.1115/1.3087540.

[36] Fan, Q. (2011). Advanced developments in computerized design and manufacturing of spiral bevel and hypoid gear drives. Applied Mechanics and Materials, vol. 86, p. 439-442, DOI:10.4028/www. scientific.net/AMM.86.439.

[37] Fong, Z.H. (2000). Mathematical model of universal hypoid generator with supplemental kinematic flank correction motion. Journal of Mechanical Design, vol. 122, no. 1, p. 136-142, DOI:10.1115/1.533552.

[38] Fan, Q. (2006). Computerized modeling and simulation of spiral bevel and hypoid gears manufactured by gleason face hobbing process. Journal of Mechanical Design, vol. 128, mo. 6, p. 1315-1327, DOI:10.1115/1.2337316.

[39] Shih, Y.P., Fong, Z.H., Lin, G.C. (2007). Mathematical model for a universal face hobbing hypoid gear generator. Journal of Mechanical Design, vol. 129, no. 1, p. 38-47, DOI:10.1115/1.2359471.

[40] Vimercati, M. (2007). Mathematical model for tooth surfaces representation of face-hobbed hypoid gears and its application to contact analysis and stress calculation. Mechanism and Machine Theory, vol. 42, no. 6, p. 668690, DOI:10.1016/j.mechmachtheory.2006.06.007.

[41] Shih, Y.P., Fong, Z.H. (2008). Flank correction for spiral bevel and hypoid gears on a six-axis $\mathrm{CNC}$ hypoid generator. Journal of Mechanical Design, vol. 130, no. 6, p. 062604-1-062604-11, DOI:10.1115/1.2890112.

[42] Simon, V.V. (2010). Advanced manufacture of spiral bevel gears on $\mathrm{CNC}$ hypoid generating machine. Journal of Mechanical Design, vol. 132, no. 3, p. 031001-1-031001-8, DOI:10.1115/1.4001130.

[43] Litvin, F.L., Fuentes, A., Hayasaka, K. (2006). Design, manufacture, stress analysis, and experimental eests of low-noise high endurance spiral bevel gears. Mechanism and Machine Theory, vol. 41, no. 1, p. 83118, DOI:10.1016/j.mechmachtheory.2005.03.001.

[44] Xie, S.X. (2013). A genuine face milling cutter geometric model for spiral bevel and hypoid gears. International Journal of Advanced Manufacturing Technology, vol. 67, no. 9-12, p. 2619-2626, DOI:10.1007/s00170-012-4678-y.

[45] Di Puccio, F., Gabiccini, M., Guiggiani, M. (2005). Alternative formulation of the theory of gearing.
Mechanism and Machine Theory, vol. 40, no. 5, p. 613637, DOI:10.1016/j.mechmachtheory.2004.10.003.

[46] Di Puccio, F., Gabiccini, M., Guiggiani, M. (2007). An invariant approach for gear generation with supplemental motions. Mechanism and Machine Theory, vol. 42, no. 3, p. 275-295, DOI:10.1016/j. mechmachtheory.2006.03.017.

[47] Di Puccio, F., Gabiccini, M., Guiggiani, M. (2005). Comparison of different methods in gear curvature analysis using a new approach. Proceedings of the Institution of Mechanical Engineers, Part C: Journal of Mechanical Engineering Science, vol. 219, no. 11, p. 1279-1294, DOI:10.1243/095440605X31986.

[48] Litvin, F.L., Fuentes, A. (2004). Gear Geometry and Applied Theory. 2nd ed. Cambridge University Press, Cambridge, DOI:10.1017/CBO9780511547126.

[49] Chen, N. (1998). Curvatures and sliding ratios of conjugate surfaces. Journal of Mechanical Design, vol. 120, no. 1, p. 126-132, DOI:10.1115/1.2826664.

[50] Wu, D.R., Luo, J.S. (1992). A Geometric Theory of Conjugate Tooth Surfaces. World Scientific, Singapore.

[51] Di Puccio, F., Gabiccini, M., Guiggiani, M. (2006). Generation and curvature analysis of conjugate surfaces via a new approach. Mechanism and Machine Theory, vol. 41, no. 4, p. 382-404, DOI:10.1016/j. mechmachtheory.2005.07.008.

[52] Huston, R.L., Coy, J.J. (1981). Ideal spiral bevel gears - a new approach to surface geometry. Journal of Mechanical Design, vol. 103, no. 1, p. 127-132, DOI:10.1115/1.3254845.

[53] Tsai, Y.C., Chin, P.C. (1987). Surface geometry of straight and spiral bevel gears. Journal of Mechanisms, Transmissions and Automation in Design, vol. 109, no. 4, p. 443-449, DOI:10.1115/1.3258815.

[54] Li, Q., Weng, H.S., Ju, H.J., Wang, G.P. (2008). Research on the location and the movement relationship between cutter and workpiece in the processing technology of logarithmic spiral bevel gear. Journal of Shenyang Jianzhu University (Natural Science), vol. 24 , no. 5, p. 881-885.

[55] Ju, H.J. (2009). The Processing Method of Logarithmic Spiral Bevel Gear. MSc's Thesis, Inner Mongolia University of Science and Technology, Baotou.

[56] Alves, J.T., Guingand, M., de Vaujany, J.P. (2013). Designing and manufacturing spiral bevel gears using 5-axis computer numerical control (CNC) milling machines. Journal of Mechanical Design, vol. 135, no. 2, p. 024502-1-024502-6, DOI:10.1115/1.4023153.

[57] Duan, Z.Y., Liu, J., Wu, H.J., Zheng, P., Wei, Y. (2002). Study of driving principle of loxodrome bevel gear with normal circular-arc profile. Journal of Dalian University of Technology, vol. 42, no. 11, p. 697-700.

[58] Duan, Z.Y., Zhao, X.P., Fu, J.S., Liu, J. (2005). Study on NC machining of normal circular-arc bevel gears. China Mechanical Engineering, vol. 16, no. 17, p. 1570-1572.

[59] Duan, Z.Y., Chen, H.J., Ju, Z.L., Liu, J. (2012). Mathematical model and manufacture programming of 
loxodromic-type normal circular-arc spiral bevel gear. Frontiers of Mechanical Engineering, vol. 7, no. 3, p. 312-321, DOI:10.1007/s11465-012-0308-5.

[60] Al-Daccak, M.J., Angeles, J., González-Palacios, M.A. (1994). The modeling of bevel gears using the exact spherical involute. Journal of Mechanical Design, vol. 116, no. 2, p. 364-368, DOI:10.1115/1.2919387.

[61] Shunmugam, M.S., Rao, B.S., Jayaprakash, V. (1998). Establishing gear tooth surface geometry and normal deviation Part II - bevel gears. Mechanism and Machine Theory, vol. 33, no. 5, p. 525-534, DOI:10.1016/S0094114X(97)00076-1.

[62] Suh, S.H., Jih, W.S., Hong, H.D., Chung, D.H. (2001). Sculptured surface machining of spiral bevel gears with CNC milling. International Journal of Machine Tools and Manufacture, vol. 41, no. 6, p. 833-850, DOI:10.1016/S0890-6955(00)00104-8.

[63] Suh, S.H., Jung, D.H., Lee, E.S., Lee, E.S. (2003). Modeling, implementation, and manufacturing of spiral bevel gears with crown. International Journal of
Advanced Manufacturing Technology, vol. 21, no. 1011, p. 775-786, DOI:10.1007/s00170-002-1393-0.

[64] Tsai, Y.C., Hsu, W.Y. (2008). The study on the design of spiral bevel gear sets with circular-arc contact paths and tooth profiles. Mechanism and Machine Theory, vol. 43, no. 9, p. 1158-1174, DOI:10.1016/j. mechmachtheory.2007.08.004.

[65] Safavi, S.M., Mirian, S.S., Abedinzadeh, R., Karimian, M. (2010). Use of PLC module to control a rotary table to cut spiral bevel gear with three-axis CNC milling. International Journal of Advanced Manufacturing Technology, vol. 49, no. 9-12, p. 1069-1077, DOI:10.1007/s00170-009-2466-0.

[66] Zhang, X.C., Wang, X., Yu, L.J., Yang Z.J. (2012). Study on the generation of spiral bevel gears with spherical involute tooth profile by the tracing line. Proceedings of the Institution of Mechanical Engineers, Part C: Journal of Mechanical Engineering Science, vol. 226, no. 4, p. 1097-1106, DOI:10.1177/0954406211419050. 